\title{
SOB(RE) O TEXTO: O DOMÍNIO DO SIGNIFICANTE*
}

Maria Alice de Sousa Carvalho**

\section{RESUMO}

O presente trabalho propõe uma reflexão sobre a produção textual, recortando, para efeito da discussão, textos produzidos por crianças da segunda série do ensino fundamental, colhidos na experiência que desenvolvi com leitura e escrita, no Centro de Ensino e Pesquisa Aplicada à Educação (CEPAE), unidade da Universidade Federal de Goiás (UFG), durante o ano de 1997. Filiando-me aos referenciais teóricos da lingüística estrutural e da psicanálise lacaniana, parti da hipótese de que a língua tem um funcionamento próprio que captura o sujeito e, nesse sentido, comanda o movimento das unidades lingüístico-discursivas na constituição de textos. Esteve em foco, na experiência, inserir o aluno em um universo textual. Com a imersão em atividades constantes e diárias de leitura e escrita, observei o movimento dos significantes dos textos circulados, compondo, com semelhança e diferença, os textos das crianças. Foi possível, portanto, reconhecer a relação de implicação entre sujeito e linguagem e considerar o texto como efeito do trabalho do significante.

Palavras-chave: linguagem; aquisição; escola.

Como professora de língua portuguesa nas séries iniciais do ensino fundamental sempre estive envolvida com questões teórico-metodológicas sobre produção textual, ora para planejar situações de leitura e escrita de textos, ora para interpretar as produções das crianças. Tenho acompanhado, nos últimos anos, inúmeros estudos e pesquisas realizados, em diferentes abordagens, que, implícita ou explicitamente, discutem e

\footnotetext{
* Artigo recebido em 5/5/2005 e aprovado em 29/7/2005.

** Mestre em Educação e professora do Centro de Ensino e Pesquisa Aplicada à Educação da UFG. E-mail: masc@cultura.com.br
} 
sustentam as práticas textuais realizadas nas escolas. A grande maioria dessas investigações recorre à psicologia cognitivista para discutir o trabalho com textos, e suas proposições sobre produção textual ordenamse segundo pares de oposições excludentes. Dentre eles, destacam-se: linguagem e pensamento, escrita de criança e de escritor proficiente, não-texto e texto, desvio e norma, metáfora e literalidade.

A lingüística textual, por exemplo, que tem atualmente fornecido, de um modo geral, o quadro teórico no campo dos estudos sobre questões de textualidade, perpetua essas oposições. Para ela, a linguagem é um instrumento de ação no meio social e, por isso, só ocorre por meio de enunciados verbais portadores de significados que possam atender a intenções de comunicabilidade e/ou interação social. Parte-se da evidência de que o homem que fala utiliza a língua para realizar, de forma compreensiva e adequada em relação aos seus parceiros, e utilizando enunciados comunicativos (potencialmente) coerentes, uma intenção de comunicação e/ou atuação (= intenção comunicativa) (SCHMIDT, 1978, p. 18).

Esse entendimento considera que o potencial significativo da linguagem está, portanto, a serviço da comunicabilidade e da intencionalidade. Assim, para aprender a escrever, a criança deve construir um conjunto de opções da linguagem por meio da participação em eventos comunicativos que se constituem pela funcionalidade.

Quando a criança aprendeu a usar a língua até certo ponto em qualquer dessas funções, por mais limitados que sejam os recursos gramaticais e lexicais de que pode lançar mão, então ela construiu um potencial de significado para essa função e dominou pelo menos uma exigência estrutural mínima - pode tratar-se de uma 'configuração' de um só elemento - para efeitos de expressá-lo (HaLliday, 1978, p. 142-143).

Essa compreensão indica que a aquisição da linguagem, oral e/ou escrita, ocorre valendo-se da apreensão de sua funcionalidade. Nesse sentido, propõe-se que, para analisar o texto da criança, ele seja colocado em relação com o texto do escritor proficiente. O texto de um escritor proficiente pode ser reconhecido por apresentar uma regularidade, por meio do domínio de normas, cujo funcionamento registra a literalidade, portanto, um sentido único e estável. Esse texto, melhor dizendo, não apresentaria a diferença, a metáfora, o desvio - características inerentes ao texto de uma criança, pois, supostamente, não atenderia aos critérios da comunicabilidade e da intencionalidade necessários à produção textual. 
Assim, o trabalho com a linguagem escrita deve privilegiar o texto, sobretudo, por apresentar-se como uma unidade portadora de significado e por ser produto de um contexto de interação social. Procura-se, então, desenvolver as práticas em sala de aula, utilizando-se de um repertório textual diversificado, sempre contemplando, prioritariamente, o aspecto funcional, comunicativo e interativo da linguagem.

Acredita-se que, por meio de exercícios de análise e reflexão sobre as características dos textos, os alunos vão apreender seus usos e significados e, por isso, adquirir capacidade para utilizar eficazmente as modalidades apresentadas, assim como as regras lingüísticas adequadas. Está em foco, nas práticas pedagógicas, um trabalho de conscientização das regras lingüísticas constitutivas do texto a partir da apreensão dos significados a serem veiculados, de modo específico, pelos diversos gêneros.

Com base nessas idéias, as práticas pedagógicas de produção textual são realizadas nas escolas brasileiras e sob sua influência foi elaborado o Parâmetro Curricular Nacional de Língua Portuguesa (PCN de Língua Portuguesa), o que implica uma maior divulgação desses pressupostos teóricos e metodológicos.

Entretanto, seria o texto apenas um recurso pelo qual se alcança a aprendizagem da língua, da história, das idéias sobre o mundo que nos rodeia? Que efeitos uma prática de ensino que propicie a imersão dos alunos em textos pode ter sobre a aquisição e o desenvolvimento da escrita? A relação da criança com o texto é direta e reflexiva, ou seja, depende de um processo meramente cognitivo? Como o texto, circulado em sala de aula, afeta a criança? Será que todas são afetadas por ele da mesma maneira? Na especificidade da língua, a letra, o som e o significado contêm uma certa substancialidade que pode ser captada pela criança?

Considero que as noções de língua e de inconsciente apresentadas, respectivamente, pela psicanálise lacaniana e pela lingüística estrutural permitirão uma maior reflexão sobre o processo de aquisição de linguagem escrita, particularmente, sobre a produção textual. Com a hipótese de que a língua tem um funcionamento próprio e captura o sujeito e, nesse sentido, comanda o movimento das unidades lingüístico-discursivas na constituição de textos, pude realizar uma experiência com leitura e produção de textos, durante o ano de 1997, em uma turma de segunda série do ensino fundamental, frequientada por vinte crianças, cuja idade variava entre sete e nove anos, no Centro de Ensino e Pesquisa Aplicada à Educação (Cepae), unidade da Universidade Federal de Goiás (UFG). 
Assim sendo, durante a experiência, esteve em foco inserir o aluno em um universo textual, ou seja, promover uma imersão em atividades constantes e diárias de leitura e escrita, através de projetos que objetivavam uma circulação de diferentes textos, abordando os temas trabalhados nas disciplinas - Estudos Sociais, Ciências, Matemática e Português. Pretendia ampliar e oferecer uma propagação de significantes, possibilitando a inserção da criança em uma rede intertextual, para que, de algum modo, um ou outro significante acabasse afetando-a, sem apelar para um suposto trabalho de conscientização das regras e/ou dos gêneros textuais.

No projeto, Planeta Terra, nosso lar, desenvolvido por aproximadamente três meses, histórias, poesias, músicas, informações e relatos relacionados ao nosso planeta, como elementos e fenômenos naturais (astros, dia, noite etc.), eram lidos diariamente em sala de aula, e os comentários que surgiam dessas leituras, por parte dos alunos, eram levados em consideração. Com eles, os alunos eram convidados a escrever, ora discutindo e comentando suas idéias sobre o texto lido, ora aproveitando determinadas passagens para compor outros textos, ampliando e estabelecendo outras relações. Algumas crianças, muitas vezes, chegavam a "copiar" determinados trechos, o que era permitido. Afinal, como se pode escrever sem apelar para outros textos?

Durante esse projeto, foram desenvolvidas muitas atividades de leitura e produção de poesias com a intenção de aproximar as crianças de um outro repertório textual, no entanto sem a preocupação de saberem as "regras" de composição de textos poéticos. Foi selecionado, pois, um repertório diversificado de alguns autores como Manuel Bandeira, Mário Quintana, Vinicius de Moraes, Silvia Orthof e José Paulo Paes, cujas poesias discutiam temas sem cair na superficialidade e apresentavam um funcionamento lingüístico em que os significantes "brincam", constroem metáforas e desconstroem critérios e padrões ilusoriamente estabelecidos. Além disso, um dos fatores que me levou a trabalhar com poesias, sem ser o mais importante, foi a possibilidade de escolher textos que abordavam os temas do projeto, valorizados por um outro ângulo, o poético, e tive o cuidado de não didatizar as poesias, ao contrário do que geralmente a escola vem fazendo com esses textos - tomando-as como mero suporte didático para desenvolver exercícios de metalinguagem e/ ou metacognição. Dessa forma, ampliava-se a rede intertextual dos assuntos, promovendo o estabelecimento de novas redes significativas. 
Esse trabalho com poesias permitiu um movimento de grande produção textual de alguns alunos. Apresento, a seguir, um texto de Ricardo, que produziu muito nesse período. Se antes ele quase não lia e escrevia, com a imersão em poesias começou a escrever: nas capas das pastas de tarefas, em folhas destacadas etc. Quase todo dia chegava à escola com algum texto.

Noiti dia

Anoitécéu na araguaia uma noi-

ti tristé éma uma ilhas

énvolta do mar

én uma baia.

Pasou o tenpu.

En uma moiti anoitéseu uma noiti.

bela noiti bélo dia iscoreu sani-

ge da noiti morta pelo dia tristeza alégria

dépois muita alégria novo vida

novo luar ar.

Amanhéseu o mar

boua noiti bon dia tatatata tarataraaran tata

testo o leve tara

Poesia noite dia tarata

tantan

Tésto o luar

En un belo di amanhésu uma

eclípsé adivinha quén reclamou.

Eclaro qui foi o dia ai ali

como ousa atrapalhar o méu dia.

Respodeu a lua aquéli dia istava

clato.

O sol respondéu éu nunca atrapalhé

i sua noiti alu falo u é verdadi

(Ricardo, 16 nov. 1997)

Como se pode observar, Ricardo foi inscrito pelas poesias, isto é, foi contagiado pelas relações que os significantes "poéticos", levados à 
sala de aula, provocaram, além, é claro, dos textos informativos trabalhados nesse período. A partir deles, produziu outros textos, revelando-se como alguém que escreve.

Nota-se que os temas "noite", "dia" e "eclipse", discutidos nos textos informativos, estabeleceram novas relações e determinaram um movimento em direção a um enfoque poético, como nos fragmentos das linhas 7, 8 e 9 . O texto apresenta cadeias significantes em constituição, permeáveis a outras cadeias e, como diz Lemos (1999), evoca elementos arbitrariamente, efetua substituições e deslocamentos vários. $\mathrm{O}$ texto traz uma oposição de dia/noite e vida/morte, resultado de um processo determinado pela metáfora e metonímia, efeito das leis gerais da linguagem.

Segundo Jakobson, as unidades lingüísticas convocam outras, por uma similaridade qualquer, por efeito posicional ou semântico. Esse processo de substituição provoca a metáfora. De uma outra maneira, as unidades lingüísticas "chamam" outras, constituindo uma relação sequiencial, de contigüidade posicional ou semântica, o que determina a metonímia.

Para exemplificar esses processos, Jakobson (1988) relata uma pesquisa psicológica, aplicada em crianças, cujo teste consistia em pedir que elas exprimissem verbalmente o que lhes viesse à cabeça, diante de um nome a elas apresentado. Suas respostas variaram diante da apresentação da palavra "choupana". Elas diziam: "queimou", "é uma pobre casinha", "cabana", "toca". Os dois primeiros exemplos demonstram uma relação de contigüidade (metonímia), e os dois últimos, uma relação de substituição (metáfora). É interessante destacar que as relações entre os processos metonímicos e metafóricos são por demais próximos, como se pode observar em "é uma pobre casinha". Ao mesmo tempo que estabelece uma relação de contigüidade, os termos "pobre" e "casinha" apontam uma relação de substituição, o que permite constatar que o processo metonímico também está presente em um processo metafórico e vice-versa. De acordo com Jakobson (1988), esses processos estão constantemente em ação, isto é,

Uma vez que a todo nível verbal - morfológico, léxico, sintático e fraseológico - uma ou outra dessas duas relações (similaridade e contigüidade) pode aparecer - e cada qual num ou noutro de seus aspectos - uma gama impressionante de configurações possíveis se cria. (1988, p. 57) 
Os processos metafóricos e metonímicos, conforme o autor, definem a produtividade lingüística, e a predominância de um deles aponta igualmente o estilo de um determinado escritor. O movimento de seleção e de combinação entre as unidades lingüístico-discursivas leva ao questionamento do papel atribuído à intenção e à consciência resultante das interações com os usos e/ou as funções da linguagem, que veiculariam significados possíveis de serem apreendidos pela criança na produção textual.

Pode-se dizer que o texto de Ricardo foi determinado, concomitantemente, pela relação de alienação e separação ${ }^{1}$ com o Outro/universo simbólico. As relações significantes provocadas pelas atividades desenvolvidas em sala de aula, como se pode notar, desdobraram-se em muitos aspectos, impossibilitando que sejam consideradas como resultado apenas de um processo consciente dos aspectos textuais. Por isso, não se deve esperar uma atitude reflexiva do sujeito em relação à linguagem para garantir, por si só, a apropriação de um conhecimento sobre a língua escrita. As produções das crianças evidenciam que o sujeito não se insere no movimento da escrita, sabendo de antemão o que fazer e o que dizer. Como define Barthes, um texto é traçado por duas margens:

Uma margem sensata, conforme, plagiária (trata-se de copiar a língua em seu estado canônico, tal como fixada pela escola, pelo uso correto, pela literatura, pela cultura), e uma outra margem, móvel, vaga (apta a tomar não importa quais contornos) que nunca é mais do que lugar de seu efeito lá onde se entrevê a morte da linguagem. (1992, p. 12)

Conforme o texto visto, recortes, reinscrições, novas combinações e substituições apareceram de forma singular, apresentando-nos a inscrição do Outro, ou melhor, dos textos com os quais Ricardo teve contato. Sua produção foi comandada pelas leis da linguagem, metáfora e metonímia.

Em sala de aula, os textos apresentavam-se como significantes, e a produção de cada criança, independentemente de uma negociação coletiva sobre o seu sentido, era efeito das novas relações estabelecidas. Muitas delas constituídas sem aquela lógica linear e horizontal, que supostamente apareceria na superfície do texto, tal como enfatiza algumas propostas pedagógicas atuais sob a orientação da lingüística textual. Para exemplificar, vejamos o texto, a seguir, de Diogo, produzido após uma 
apresentação dos índios e depois de entrar em contato com vários textos sobre a realidade brasileira da vida indígena:
26 Eu achei o ídio Karajás muito calado e as arma
27 e a, fleche, remo, arca, berso, furo peito,
28 mizica Karajás e Xavantes poque as familias dele
29 e indio Karajás e Xavantes e deverete dos outo
30 as armsa que ele mata os aminais como.
31 primeiro ver que eu vir um índio pintado
32 e índios que vei do mato groso e do chingu e
33 lei inianos eles vei para apresetar para ganha
34 dinheiro para ajudar a familia dele.

(Diogo, 24 abr. 1997)

Pode-se notar que o texto apresenta algumas lacunas, por exemplo nas linhas 26, 28, 30 e 31. Esses cortes são decorrentes do fato de a criança não conhecer, ainda, os recursos da língua escrita e/ou não ter consciência das diferenças entre um texto oral e um texto escrito? A criança, afirma Kock,

continua a empregar em suas produções os recursos próprios da oralidade: por exemplo, não atina, ainda, com a necessidade de representar verbalmente tudo que está presente ou implicado na situação comunicativa, com o fato de não ter o interlocutor diante de si e/ou de que o leitor de seu texto não é um observador co-presente ao desenrolar dos fatos. (1995, p. 117)

Entretanto, observando esse texto, percebe-se que os enunciados aparentemente interrompidos estabelecem continuidade. Por exemplo, a linha 26 estabelece relação com as linhas 28,33 e 34 e indica uma possível unidade, isto é, um efeito de sentido, valendo-se do movimento de retroação e progressão, conforme descreve Lacan (1992). Essas passagens são efeitos de um entrecruzamento de cadeias sob e sobre o texto, sugerindo que os vínculos entre os enunciados podem ser explicitados desde que se considerem cadeias latentes e não uma linearidade seqüiencial e horizontal. Para dizer melhor, os enunciados, aparentemente inconclusos, estão submetidos ao movimento da língua, em que um elemento opõe-se ao que o precede e ao que o segue e até a ambos, de maneira que dissolvem o padrão ininterrupto. Além disso, a tensão e/ou corte entre os enunciados estabelece a divisão do sujeito, provocada pela sobredeterminação do 
Outro. Como efeito do Outro, Diogo não reconhece as diferenças entre os enunciados e suas aparentes rupturas. Como recomenda Lacan:

para compreender o que se diz é necessário ver os seus substitutos, as suas ressonâncias, as suas superposições significativas. Sejam quais foram, e podemos admitir todos os contrasensos, nunca é ao acaso. Quem medita sobre o organismo da linguagem deve saber mais possível, e fazer, tanto a propósito de uma palavra quanto de um torneio, ou de uma locução, o fichário mais completo possível. A linguagem funciona inteiramente na ambigüidade, e a maior parte do tempo vocês não sabem absolutamente nada do que estão dizendo. (1992, p. 135)

Assim sendo, a presença e a ausência das unidades que constituem os textos das crianças não dependem apenas da cognição e do domínio das regras de estratégias textuais (coesão e coerência), sugeridos pela lingüística textual. A relação estabelecida pela criança, ao inserir-se, mediante textos, no movimento da linguagem, permite reconhecer a nãopossibilidade de tratar a língua como objeto de conhecimento como outro qualquer, possível de ser apreendido por processos gradativos e sistematizados. Sobre a linguagem, lembra Lacan:

Se há uma ordem de aquisição, não é certamente aquela que permitiria dizer que as crianças começam por tal elemento do estoque verbal antes que por tal outro. Há a maior diversidade. Não se pega a linguagem por uma extremidade, como certos pintores começam seus quadros pelo lado esquerdo. A linguagem, para nascer, deve sempre ser tomada em seu conjunto. (1992, p. 260)

Quem escreve? É um sujeito que não tem o controle dos significantes e não detém uma significação em primeira mão, tal como acontece na história de Gribouille, contada do seguinte modo por Lacan:

Vocês conhecem a história de Gribouille. Ele vai ao enterro, e diz Boas festas! Leva uma bronca, puxam-lhe o cabelo, ele volta para casa - Ora essa, não se diz boas festas num enterro, diz-se Deus tenha sua alma. Ele sai de novo, encontra um casamento - Deus tenha sua alma / E novos acontecimentos vão-lhe acontecer. (1995, p. 113) 
Nessa história, Lacan (1995) destaca o movimento do sujeito em relação aos significantes. Isto é, o sujeito não mantém com os significantes uma relação direta e estável. Aos saltos e aos pulos, o sujeito estabelece relações, e da mesma forma uma criança produz textos. Não se deve esperar, portanto, que, de início, ela já saiba o que fazer com as informações e/ou com os textos orais e escritos circulados em sala de aula, a exemplo do que aconteceu com Ricardo e Diogo. Após ouvir um discurso sobre a necessidade de apresentar o texto de acordo com a convenção da língua portuguesa, Ricardo apresentou um texto com todas as palavras separadas, mais ou menos assim: " $\mathrm{Eu}-\mathrm{fu}-\mathrm{i}-\mathrm{na}-\mathrm{ca}-\mathrm{sa}-\mathrm{da}-\mathrm{mi}-$ nha - a - vó". Questionado sobre o porquê dessa separação, ele respondeu: "Professora, você não me disse que ao escrever um texto temos que separar as palavras corretamente?"

Dessa forma, as relações significantes estabelecidas nas diversas atividades de leitura e produção de textos desenvolvidas pelos alunos não são previsíveis, estando, a rigor, sobredeterminadas pelo Outro. Em seus textos, nota-se uma proliferação de substituições e encadeamentos entre unidades lingüísticas, produzindo escansões, repetições e vários efeitos de sentido sob e sobre o texto.

Durante a experiência, pude constatar que as condições de produção textual desenvolvidas e as intervenções que fazia durante as aulas e, também, nos textos das crianças eram dependentes do jogo estabelecido com o Outro. Como professora, estava aprisionada, isto é, determinada pelos significantes, razão por que não havia como controlar os desvios e as respostas das crianças diante do que programava.

Nem sempre o texto selecionado e a intervenção proposta desencadeavam um movimento de coincidência entre o que foi apresentado ou pedido e o que veio como resposta. As crianças, de maneira singular, confirmavam que também o professor está sob(re) o efeito do Outro. No dizer de Ribeiro, o que se revela na relação do ato de ensinar e de aprender é, "na verdade, um logro, que, colocado no lugar da falta, deixa o sujeito sempre exposto ao equívoco" (1999, p. 133-134).

Com base nesse entendimento, o Outro inscreve-se sempre e permeia tanto a produtividade lingüística da criança quanto a relação entre o professor, o aluno e as propostas pedagógicas desenvolvidas em sala de aula. Como descreve Barthes, um sujeito está:

sempre sobre a mancha cega dos sistemas, à deriva; é um joker, um mana, um grau zero, o morto de bridge: necessário ao sentido (ao 
combate), mas ele mesmo privado de sentido fixo; seu lugar, seu valor (de troca ) varia segundo os movimentos da história, os golpes táticos da luta: pedem-lhe tudo e/ou nada. (1992, p. 48)

Nesse sentido, uma experiência textual, tal como foi desenvolvida, e os textos que dela resultaram não deixaram de revelar a imprevisibilidade que está, quando se trata de linguagem, sempre em constituição. Assim sendo, pode-se dizer que o processo de produção textual é um encontro, pelo texto/Outro, do domínio sob(re) o significante.

\section{ABSTRACT}

This study proposes a reflection on textual production. In order to provoke discussion, texts produced by second-year primary school pupils were selected. These texts resulted from an experience in reading and writing carried out with a group of the above-mentioned pupils, in the Centro de Ensino e Pesquisa Aplicada à Educação (CEPAE), at the Universidade Federal de Goiás (UFG), throughout 1997. Adopting Structural Linguistic theoretical principles as well as Lacanian Psychoanalysis, I started from the hypothesis that language has a functioning of its own which captures the subject and, hence, directs the movement of the linguistic-discursive units at the moment the text is being drawn up. This experience focused on the immersion of the student in a textual universe. Immersed in frequent daily activities of reading and writing, I observed the movement of the signifier in the texts circulating in the classroom, through the similarities and differences in the composition of the children's texts. It was therefore possible to recognize the relationship of implication between subject and language and to consider the text as an effect of the work of the signifier.

Key words: language; acquisition; school.

\section{NOTA}

1. De acordo com Lacan, alienação e separação são faces do processo constitutivo da relação do sujeito com o Inconsciente/Outro.

\section{REFERÊNCIAS}

BARTHES, R. O prazer do texto. São Paulo: Perspectiva, 1996. 
BRASIL. Ministério da Educação e Desportos (MEC). Secretaria de Educação Fundamental (SEF). Parâmetros curriculares nacionais (PCN): língua portuguesa. Brasília, 1997.

HALLIDAY, M. A. K. As bases funcionais da linguagem. In: DASCAL, M. (Org.). Fundamentos metodológicos da lingüística. Concepções gerais da teoria lingüística. São Paulo: Global. 1978, v. 1.

JAKOBSON, R. Dois aspectos da linguagem e dois tipos de afasias. In: Lingüística e comunicação. São Paulo: Cultrix, 1988.

KOCK, I. V. Aquisição da escrita e textualidade. Cadernos de Estudos Lingüísticos. Campinas, n. 29, p. 109-118, jul./dez., 1995.

LACAN, J. O seminário 3: As psicoses. Rio de Janeiro: Jorge Zahar, 1992.

. O seminário 2: O eu na teoria de Freud e na técnica da psicanálise. Rio de Janeiro: Jorge Zahar, 1995.

LEMOS, C. T. G. Em busca de uma alternativa à noção de desenvolvimento na aquisição de linguagem - Parte II. Campinas: DL/IEL/Unicamp, 1999. [Mimeo].

RIBEIRO, N. N. A. Efeito lingüístico-discursivo no jogo do ensinar e do aprender. Maceió, 1999. Dissertação (Mestrado em Educação) - Universidade Federal de Alagoas.

SCHMIDT, S. J. Lingüística e teoria de texto. São Paulo: Pioneira, 1978. 